\title{
Predicting the Typhoons in the Philippines Using Radial Basis Function Neural Network
}

\author{
Jane Colleen T. Ventura, R. B. Angelou F. Cobosa, Angie M. Ceniza, and Kris A. Capao
}

\begin{abstract}
Typhoons, also called hurricanes in the Atlantic or North Pacific, are one of the natural disasters that have caused a great amount of damage in the Philippines. A few typhoons have caused the loss of lives and the loss of resources. Over the years, several typhoon prediction models have been created through different ways such as through regression and data mining techniques. This research built a Radial Basis Function Neural Network that would predict typhoons in the Philippines. Historical typhoon data was taken from Philippines Atmospheric Geophysical and Astronomical Services Administration (PAGASA) and the historical weather data of an area in the Northwestern Pacific Basin, specifically Guam, was taken from a source online. Weather and typhoon data for the first 13 years served as training set; the remaining two years served as testing set. The accuracy of the Radial Basis Function Network was tested using cross entropy error and root mean square error. The cross entropy error is $\mathbf{1 2 0 . 9 4 1}$, and the root mean square error is 9.570 .
\end{abstract}

Index Terms-Typhoons, radial basis function neural network, cross entropy error, root mean square error.

\section{INTRODUCTION}

A typhoon, also called a tropical cyclone, is a violent storm that occurs in the Western Pacific area or the China seas. Multiple atmospheric factors may contribute to the formation of such natural disaster. Several typhoons have already made landfall in the Philippines. While some typhoons were small and left minimal or no damage, other typhoons have resulted to loss of lives and resources. One example of a catastrophe created by a typhoon happened on the 8th of November 2013 when typhoon Yolanda (also called Typhoon Haiyan) set foot in the Philippine islands. With a strength equivalent to a Category 5 storm [1], its highest recorded wind speed was $315 \mathrm{~km} / \mathrm{h}$ resulting to a surge in sea level of over 13 feet. After the phenomenon, fear has struck some of the people in the Philippines that a typhoon with such strength may appear once again and bring destruction to the country. The lack of preparedness and information during those events and the scary probability of the country going through a similar storm sparked the researchers to conduct a study on predicting future typhoons and their characteristics.

Some have dedicated their study to the prediction of typhoon/hurricane patterns. Majority of the previous studies have utilized the historical data of the area for which a prediction is to be done to find out a pattern in the arrival of

Manuscript received September 18, 2017; revised December 12, 2017.

The authors are with University of San Carlos, Cebu City, 6000, Philippines (e-mail: janecolleenventura@gmail.com, racobosa@gmail.com, amceniza@usc.edu.ph, kris.capao@gmail.com). tropical cyclones. The accuracy of the predictions done for typhoons/tropical cyclones might vary from each another, this is mainly because researchers use different variables, methods and solutions. Previous studies have taken different approaches in the process of creating a prediction. One study utilized a track-pattern-based model that uses a fuzzy c-means clustering of historical TC tracks and a hybrid statistical-dynamical prediction [2]. Another study used data mining techniques and classification rules to predict the intensification of a tropical cyclone [3]. Taking into consideration relationships between typhoons might be a possible solution to create a more standardized and accurate prediction of a typhoon.

This research built an artificial neural network that will predict future typhoons to set landfall in the Philippines with the use of the data gathered. Data mining methods will also be used in the process. This research aims to produce an output of predicted typhoons, with their specifications, through the results of the artificial neural network.

\section{RELATED REVIEW OF LITERATURE}

These are the related review of literature used in this research.

\section{A. Typhoons}

A typhoon is an extremely large, powerful, and destructive storm that occurs especially in the region of the Philippines or the China Sea [4]. It is a weather phenomenon equivalent to a hurricane or a cyclone and is recognized as a warm-core system that develops from a pre-existing perturbation [5]. These typhoons may develop at different paces. Some typhoons may develop slowly but grow cause damage. An instance of this is Typhoon Beth, a typhoon that occurred on October 1996. For a week, it developed very slowly. It passed over Guam, and became a typhoon in the Philippine Sea then passed over Luzon where it caused 3 deaths and property damage in Cagayan [6]. Over the years, a dramatic increase in the number of people and the value of properties have been observed in typhoon-prone areas. This has prompted more attention on the characterization of the climatology of tropical cyclones [7]. Several researchers have dedicated a study on the cause, effect and relationship of typhoons with the different weather conditions. El Niño is a climate cycle that was noted to positive effect on a typhoon such that it can increase the intensity. However, it was discovered that it may also affect the typhoon negatively since it can act as a damper to slow it down [8]. There were also some factors that were thought to affect but did not. An example of this is the local sea surface 
temperature. The local sea surface temperature did not have any significant correlation with the number of intense tropical cyclones in the Northwestern Pacific. Because of the lack of awareness of the different factors that affect typhoons, some models generate errors [9].

Various machine learning algorithms are used to create different typhoon prediction systems. An example of this is the hurricane intensity prediction through the Weight Feature Learning-Extensible Markov Model. This model uses data mining techniques and a genetic algorithm to provide the best solution [10]. A prediction of the trajectory is also viable through the use of data mining and association analysis. Here, the Apoiri algorithm is important since with it, movement rules may be generated [11]. Trajectory data mining may also be a feasible way to predict the destination. Here, the mobility pattern of a moving object is predicted using next check-in data [12]. A prediction of the characteristic factors of a tropical cyclone is also feasible through a methodology combining data mining technology with statistical methods [13].

\section{B. Radial Basis Function Neural Network}

Through the years, researches on directing and predicting the future have increased. Most methodologies have been done through statistical techniques. However, Artificial Neural Networks have emerged and challenged these methods. Artificial neural networks are mathematical models inspired by the organization and functioning of biological neurons [14]. The computing systems profit from understanding how humans perform these tasks, and simulating these processes to the extent allowed by physical limitations which necessitates the study and simulation of Neural Networks. In other words, it is modeled closely following the brain [15]. There are different problems to which Neural Networks can solve, one is shown through the development of a Neural Network that can be used to generate an estimation of a hurricane's central pressure and the radius to maximum winds. This model was tested with 4 historical hurricanes in the Gulf of Mexico and learned through a historical data set for the same area [16]. Besides its different types of uses, it also has different types or kinds. One of which is the Radial Basis Function Neural Network. The Radial Basis Functions emerged as a variant for a two layer neural network. It is an artificial neural network that uses a radial basis function kernel [17]. Despite it possessing only one hidden layer, it can solve complex problems similar to a neural network with multiple intermediary layer due to its capability to transform nonlinear input into linear output [18]. It contains a radial activated function in each of the hidden units and the weighted sum of the output units in the hidden layer is implemented by the output units [19]. The Radial Basis Function Neural Network has the advantage of a simpler structure and a faster learning speed. It also has a concise mathematical form and can also solve the small sample, nonlinear, dimension and local minima, leading it to be widely used [20].

\section{METHODOLOGY}

This section discusses the conceptual framework of this research in order to predict the typhoons in the Philippine using Neural Network. See Fig. 1 for the conceptual framework of the said research.

\section{A. Collect Typhoon and Weather Data}

Over 215 typhoon data rows and 219 weather data rows were collected. The researchers visited the Cebu branch of the PAGASA office to obtain the typhoon data from year 2000 to 2015.

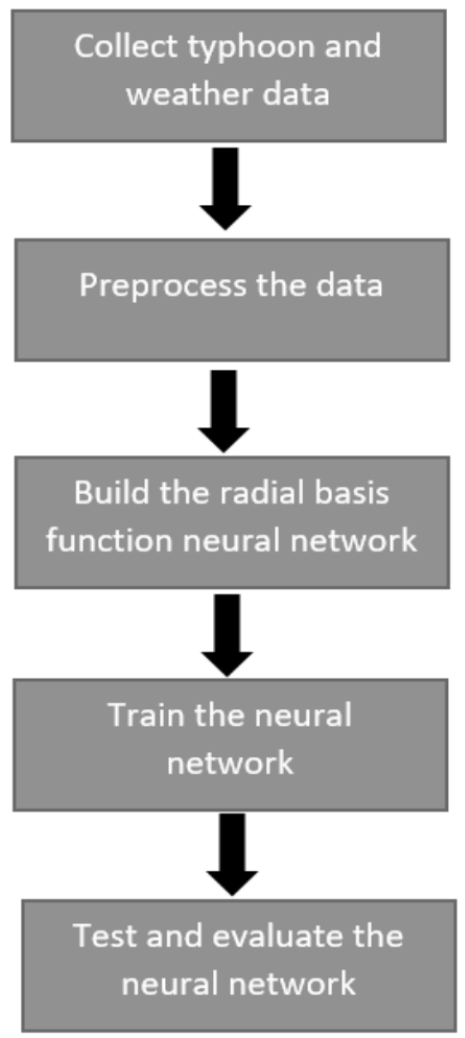

Fig. 1. Conceptual framework

And, there were 1,291 data rows collected from the weather data of Guam (i.e. www.wunderground.com and tidesandcurrents.noaa.gov). These served as the variables for the typhoon and weather data.

Typhoon \{Duration, Maximum winds over water, Maximum winds over land, Maximum Mean sea level pressure on land, Mean sea level pressure on water, Maximum Rainfall, Category\}

Weather \{Temperature, Dew Point, Humidity, Sea Level, Wind, Precipitation, Direction, Gusts, Air and Water Temperature\}

\section{B. Preprocess the Data}

The researchers used Python to automate the preprocessing. In order for the data to be suitable for the Neural Network, it involves the following steps: (1) Scaling the data; (2) Retrieving the relevant weather data, (3) Averaging the weather data retained; and (4) Splitting the data (testing and training).

1) Scaling the data

2) The weather data (i.e. temperature, dew point, relative humidity, sea level pressure, wind, direction, air temperature, gusts, precipitation, water temperature) was scaled into smaller values. Some typhoon data (i.e. pressure, rainfall, mean sea level 
pressure) was preprocessed as well.

3) Retrieve relevant weather data

4) Retrieved weather data from Guam encompasses 5 days before the start of the actual typhoon in the Philippines.

5) Averaging the data

6) A five-day weather data, corresponding to a typhoon, was averaged to avoid too many variables during the training and testing of the neural network.

7) Splitting data (training and testing)

8) The weather and typhoon data were split into training set and testing set. The first 13 years was the training set and the remaining 2 years was the testing set. This training set was then fed to the radial basis function neural network.

\section{Build the Radial Basis Function Neural Network}

In building the radial basis function neural networks, a few methods were used. It started with the initialization of values such as the centers, the weight, and the input and output data. The input and output data were then sent to the training function where the centers were chosen through the K-means clustering using Lloyd's algorithm. See Table I for the summary of the centers that were generated through Lloyd's algorithm.

TABLE I: CENTERS OBTAINED FROM K-MEANS CLUSTERING

\begin{tabular}{llllllllll}
\multicolumn{10}{c}{ TABLE I: CENTERS OBTAINED FROM K-MEANS CLUSTERING } \\
\hline \hline 3 & 6.8 & 6.8 & 1 & 2.4 & 1.3 & 7.8 & 12.1 & 1.6 & 2.2 \\
2.9 & 6.7 & 6.7 & 1 & 2.5 & 2.6 & 5.6 & 42.2 & 1.2 & 3.3 \\
2.9 & 6.1 & 6.1 & 1 & 2.3 & 2.2 & 13. & 28.9 & 1.1 & 0 \\
& & & & & & 5 & & & \\
3 & 6.2 & 6.2 & 1 & 2.1 & 2.5 & 13. & 38.7 & 0.9 & 0.6 \\
& & & & & & 6 & & & \\
2.9 & 6.8 & 6.8 & 1 & 1.8 & 2.1 & 5.6 & 30.9 & 0.9 & 2.3 \\
2.9 & 7 & 7 & 1 & 1.8 & 2.3 & 9.5 & 2.7 & 1.9 & 4.2 \\
2.9 & 6.5 & 6.5 & 1 & 2.4 & 2.3 & 3.3 & 20.4 & 1.3 & 2 \\
3 & 6.6 & 6.6 & 1 & 2.9 & 2.1 & 4.8 & 50 & 1 & 2 \\
2.9 & 6.5 & 6.5 & 1 & 2.2 & 1.8 & 9.6 & 19.5 & 1.9 & 2.4 \\
3 & 7 & 7 & 1 & 1.8 & 1 & 0.5 & 6.3 & 0.5 & 3 \\
\hline \hline
\end{tabular}

$\beta$ - beta value represents the width of Gaussian.

The Beta value was then calculated using the formula below:

$$
\beta=\frac{1}{\left(2 *\left(\sigma^{2}\right)\right)}
$$

Then, together with the centers, the input values were sent to the activation function. After the activation values were generated, the weights were taken using Gradient Descent and dot multiplication. Once the training was finished, the weather testing set was multiplied through dot multiplication with the weights. See Table II for the weights obtained through gradient descent. This resulted into a table of data that contains the category $(0.1$ - tropical depression, 1 tropical storm, 2 - severe tropical storm, 3 - typhoon), maximum winds over land, maximum winds over water, mean sea level pressure on land and water, rainfall, and the duration of the typhoon/tropical storm/tropical depression.

\begin{tabular}{lllllll}
\multicolumn{6}{c}{ TABLE II: WEIGHTS OBTAINED THROUGH GRADIENT DESCENT } \\
\hline \hline 5.79 & 15.05 & 14.51 & 12.39 & 9.23 & 29.03 & 2.39 \\
5.65 & 14.18 & 12.68 & 14.35 & 11.69 & 31.74 & 2.5 \\
5.33 & 11.25 & 10.47 & 13.78 & 3.4 & 27.55 & 2.51 \\
6.05 & 12.53 & 10.63 & 13.38 & 11.3 & 26.17 & 3.02 \\
9.02 & 13.94 & 22.2 & 18.18 & 19.23 & 50.61 & 3.32 \\
6.79 & 5.74 & 13.13 & 11.48 & 1.7 & 31.98 & 2.73 \\
6.73 & 9.06 & 9.33 & 16.13 & 7.8 & 25.54 & 0.93 \\
\hline \hline
\end{tabular}

\begin{tabular}{lllllll}
\hline \hline 10.04 & 18.29 & 15.7 & 21.08 & 15.69 & 42.21 & 3.15 \\
3.89 & 51 & 9.47 & 11.87 & 0.13 & 24.34 & 1.91 \\
5.55 & 16.35 & 7.28 & 6.54 & 17.44 & 36.17 & 2.51 \\
\hline \hline
\end{tabular}

Libraries such as SciPy, Scikit-learn, and Numpy were used in the process. The K-means clustering method is available in the Scikit-learn library. The other methods and equations used were coded with the help of the Numpy and SciPy library. Besides the methods named, functions for the calculation of the Beta and the activation function were also created.

\section{Test and Evaluate Neural Network}

The Neural Network's accuracy after training was tested through the solving of the cross entropy error and the root mean square error. Once the neural network was generated the predicted results, both methods were used to obtain error values. The cross entropy error totaled to 120.941 , and the root mean square error had a value of 9.570 .

$$
\begin{gathered}
\text { Cross Entropy Error }=-\sum_{i=0}^{n} \ln \left(o_{i}\right) * t_{i} \\
R M S E=\sqrt{\frac{1}{n} \sum_{i=1}^{n}\left(Y_{i}-Y_{i(s u b)}\right)^{2}}
\end{gathered}
$$

\section{RESULTS}

After training the neural network, the testing set was fed. This time, only the weather data was fed to the neural network. The input data was then multiplied using dot multiplication to the weights generated from training.

\begin{tabular}{lllllll}
\multicolumn{5}{c}{ TABLE III: } & ACTUAL OUtPUT VALUES OF THE TESTING SET \\
\hline \hline Dur & $\begin{array}{l}\text { Wind } \\
\text { (Water }\end{array}$ & $\begin{array}{l}\text { Wind } \\
\text { (Land) }\end{array}$ & $\begin{array}{l}\text { MSLP } \\
\text { (Water }\end{array}$ & $\begin{array}{l}\text { MSLP } \\
\text { (Land) }\end{array}$ & Rain & Type \\
& ) & & ) & & & \\
\hline 3 & 4 & 10 & 2.44 & 5.22 & 15 & 1 \\
2 & 10 & 10 & 5.89 & 7.44 & 20.85 & 0.1 \\
5 & 13 & 0.1 & 0.1 & 18.22 & 7 & 1 \\
2 & 18 & 13 & 20.33 & 14.11 & 16.3 & 1 \\
4 & 9 & 0.1 & 0.1 & 2.33 & 27.2 & 3 \\
5 & 9 & 18 & 11.23 & 5 & 27.19 & 3 \\
7 & 11 & 0.1 & 0.1 & 16.11 & 0.1 & 1 \\
5 & 11 & 11 & 13.11 & 11.22 & 27.43 & 1 \\
3 & 11 & 8 & 0.1 & 4.44 & 0.1 & 1 \\
5 & 9 & 11 & 5.56 & 20 & 9 & 3 \\
6 & 12 & 25 & 15.78 & 13.67 & 23.84 & 3 \\
6 & 10 & 10 & 10 & 5.11 & 17.75 & 1 \\
4 & 11 & 5 & 15.89 & 17 & 18.81 & 3 \\
3 & 10 & 0.1 & 0.1 & 3 & 14.63 & 3 \\
4 & 13 & 11 & 17.44 & 17.89 & 19.81 & 3 \\
6 & 10 & 26 & 16.78 & 6.67 & 34.06 & 3 \\
7 & 8 & 17 & 12.42 & 15.35 & 18 & 3 \\
\hline \hline
\end{tabular}

TABLE IV: PREDICTED RESULTS OF THE RBF NEURAL NETWORK

\begin{tabular}{lllllll}
\hline \hline Dur & $\begin{array}{l}\text { Wind } \\
\text { (Water) }\end{array}$ & $\begin{array}{l}\text { Wind } \\
\text { (Land) }\end{array}$ & $\begin{array}{l}\text { MSLP } \\
\text { (Water) }\end{array}$ & $\begin{array}{l}\text { MSLP } \\
\text { (Land) }\end{array}$ & Rain & $\begin{array}{l}\text { Typ } \\
\text { e }\end{array}$ \\
\hline 5.01 & 7.85 & 12.28 & 10.17 & 10.6 & 30.32 & 1.86 \\
4.52 & 7.04 & 11.09 & 9.14 & 9.61 & 27.52 & 1.67 \\
2.01 & 4.01 & 3.6 & 4.63 & 15.97 & 6.19 & 2.16 \\
2.67 & 8.2 & 4.58 & 6.51 & 23.93 & 7.23 & 3.15 \\
1.6 & 6.32 & 3.35 & 3.81 & 9.67 & 7.04 & 1.22 \\
1.14 & 5.46 & 2.2 & 2.85 & 8.86 & 4.34 & 1.07 \\
1.91 & 5.59 & 3.87 & 4.41 & 12.12 & 7.71 & 1.6 \\
2.41 & 13.76 & 4.46 & 6.3 & 21.45 & 8.55 & 2.5 \\
3.68 & 32.1 & 7.66 & 10.29 & 30.25 & 16.9 & 3.05 \\
3.07 & 26.14 & 6.43 & 8.51 & 24.54 & 14.12 & 2.5 \\
3.21 & 27.58 & 7.06 & 8.83 & 22.91 & 15.79 & 2.31 \\
3.55 & 25.89 & 7.08 & 9.59 & 29.63 & 14.66 & 3.23 \\
2.98 & 22.61 & 6.76 & 7.87 & 17.96 & 14.87 & 1.93 \\
\hline \hline
\end{tabular}




\begin{tabular}{lllllll}
\hline \hline 4.35 & 31.78 & 9.71 & 11.43 & 27.11 & 21.05 & 2.98 \\
3.76 & 26.31 & 8.37 & 9.79 & 23.04 & 17.99 & 2.59 \\
3.57 & 17.66 & 7.95 & 8.66 & 18.39 & 16.09 & 2.43 \\
3.1 & 19.96 & 6.69 & 8 & 20.18 & 13.94 & 2.34 \\
\hline \hline
\end{tabular}

The result of the dot multiplication served as the predicted values. Table III shows the actual output values and Table IV shows the summary of the typhoon data predicted by the Radial Basis Function Neural Network. Each typhoon data contained 7 variables and there was a total of 17 typhoons to be predicted giving a total of 119 variables to be predicted.

\section{CONCLUSIONS AND RECOMMENDATIONS}

This research was able to build a Radial Basis Function Neural Network that predicts typhoons given a set of weather conditions of a country that belongs to the Northwestern Pacific Basin. The Neural Network showed good results since most values predicted were within the same range or were close to the actual value. The study was able to train the Neural Network with data from year 2000 to 2013, which helps since the more data fed, the more the Neural Network can learn. The researchers were not able to create an error-free network which denotes that this can be further improved. Therefore, the study concludes that weather data from Guam can serve as parameters for the prediction of typhoons in the Philippines.

This research can be improved further by testing out other types of Neural Networks. Through this, a basis for comparison on the accuracy will be created and the best Neural Network for the data available will be realized. Another way to improve this research is to gather more data. While 13 years of data is already sizable, the Neural Network accuracy would be better enhanced by additional years of data. Since the Neural Network learns from past typhoons, this would be able to help immensely as it could increase the accuracy of the predictions.

\section{ACKNOWLEDGMENT}

We wish to thank and acknowledge the Department of Computer and Information Science in the University of San Carlos for the research opportunity. We would also like to thank Mr. Patrick Dave Woogue for giving us valuable input during our discussions about Machine Learning and Artificial Neural Networks and to Engr. Oscar Tabada and the employees of the PAGASA, Cebu branch for helping us gather data.

\section{REFERENCES}

[1] Mercy Corps. (2017). [Online]. Available: https://www.mercycorps.org/

[2] H. S. Kim, J. H. Kim, C. H. Ho, and P. S. Chu, "Pattern classification of typhoon tracks using the fuzzy c-means clustering method," Journal of Climate, 2010.

[3] K. Chatzidimitriou and A. Sutton, "Alternative data mining techniques for predicting tropical cyclone intensification," Colorado: American Association for Artificial Intelligence, 2005.

[4] Webster. [Online]. Available: https://www.merriamwebster.com/dictionary/typhoon

[5] L. F. Hubert. (1955). A case study of hurricane formation. [Online]. Available: http://www.journals.ametsoc.org/
[6] M. A. Lander, E. J. Trehubenko, and C. P. Guard, "Eastern hemisphere tropical cyclones of 1996," American Meteorological Society, vol. 127, 1999.

[7] P. Rebera, R. Garcia-Herrera, E. Hernandez, and L. Gimeno, "Northwest pacific typhoons documented by the Philippine Jesuits," Journal Of Geophysical Research, vol. 112, 2007.

[8] Z. W. Zheng, I. I. Lin, B. Wang, H. C. Huang, and C. H. Chen, "Scientific reports: Nature," Retrieved from Nature Web Site, 2015.

[9] J. L. Chan and K. Liu, "Global warming and western north pacific typhoon activity from an observational perspective," Journal of Climate, 2004

[10] Y. Su, S. Chelluboina, M. Hahsler, M. Dunham, "A new data mining model for hurricane intensity prediction.

[11] X. Dong and D. C. Pi. Novel, "Method for hurricane trajectory prediction based on data mining," Nat. Hazards Earth Syst. Sci., vol. 13, pp. 3211-3220, 2013

[12] C. Banupriya and V. Chamundeeswari, "A survey on destination prediction using trajectory data mining technique," International Journal of Engineering and Computer Science, 2016.

[13] R. Zhou, W. Gao, B. Zhang, X. Fu, Q. Chen, S. Huang, and Y. Liang. (2014). Prediction of Tropical Cyclones' Characteristic Factors on Hainan Island Using Data Mining Technology. [Online] Available: https://www.hindawi.com/

[14] T. Hill, L. Marquez, M. O'Connor, and W. Remus, "Artificial neural network models for forecasting and decision making," 1993.

[15] A. Dongare, R. Kharde, and A. Kachare, "Introduction to artificial neural network," International Journal of Engineering and Innovative Technology, vol. 2, no. 1, 2012.

[16] H. Jung and H. Das, "Estimation of hurricane parameters using artificial neural network," International Journal of Engineering Research \& Technology, 2013.

[17] D. Broomhead and D. Lowe, "Radial basis functions, multi-variable functional interpolation and adaptive networks," 1988.

[18] Y. Arora, A. Singhal, and A. Bansal, "A study of applications of RBF network," International Journal of Computer Applications, vol. 94, pp. $17-20,2014$

[19] A. G. Bors, Introduction of the Radial Basis Function (RBF) Network

[20] W. Ji, L. Sun, K. Wang, and L. Lv, "Learning methods of radial basis function neural network," Journal of Chemical and Pharmaceutical Research, vol. 8, no. 4, 2016

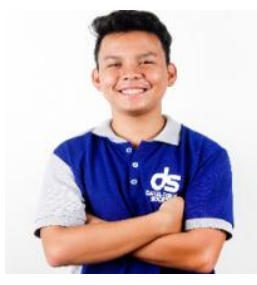

R. B. Angelou F. Cobosa was born in Ormoc city, Philippines on September 29, 1998. He is currently a $4^{\text {th }}$ year computer science student studying at University of San Carlos. He is expected to graduate by. April of the year 2018 .

$\mathrm{He}$ is interested in researches that include machine learning, data analysis and big data.

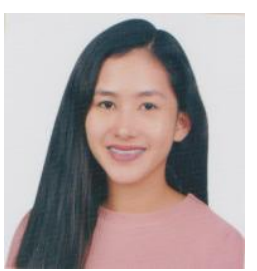

Jane Colleen T. Ventura was born in Cebu city, Philippines, in 1996. She is currently studying for a BS-computer science degree in the University of San Carlos and is expected to graduate by April 2018

She is interested in researches that include neural networks and machine learning.

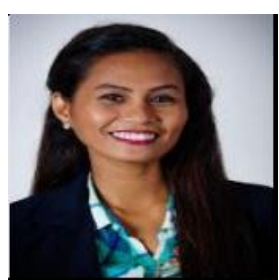

Angie M. Ceniza was born in Cebu city, Philippines on April 16, 1989.

She is currently employed in the University of San Carlos as an instructor in the Department of Computer Science. She, along with other authors, was able to publish numerous researches. Among are the few:

"G. Payusan, C. Maderazo, and A. Ceniza, "A decision support system in facilitating properties for rent using analytic Hierarchy process and goal programming," Far East Journal of Electronics and Communications, 2016;

A. Ares, A. Cantara, K. Capao, A. Ceniza, E. Mendoza, S. Polinar, T. Punzalan, M. J. Sabellano, and J. Tero, "Analyzing the correlation Amongst the students taking computing course," Far East Journal of Electronics and Communications, 2016. 
She is interested in researches that include data mining and decision support system, sentiment analysis, file management system and GIS mapping.

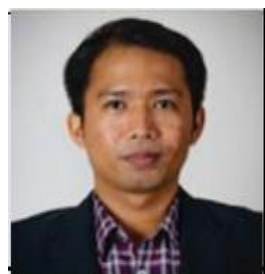

Kris A. Capao was born in Consolacion, Cebu city, Philippines on Octobor 2, 1985.

$\mathrm{He}$ is currently employed in the University of San Carlos as an Instructor in the Department of Computer Science. He along with other authors, was able to publish a couple of research papers.
Among are the researches: E. Mendoza, K. Capo, A. Ceniza, A. Cantara, J Tero, B. Balala, H. Sueno, "An empirical analysis of political party dominance in the Philippines using Markov chain and GIS mapping," in Proc. the National Conference on Information Technology Educator, Dipolog City, Philippines, 2016; K. Capao, A. Cantara, A. Ceniza, E. Mendoza, S. Polinar, and J. Tero, "Predicting academic performance with intelligence, study habits and motivation factors using naïve Bayes algorithm," International Journal of Engineering Research \& Technology, vol. 5, no. 3, pp. 182-185, 2016

His research interests include neural networks, machine learning and data mining. 